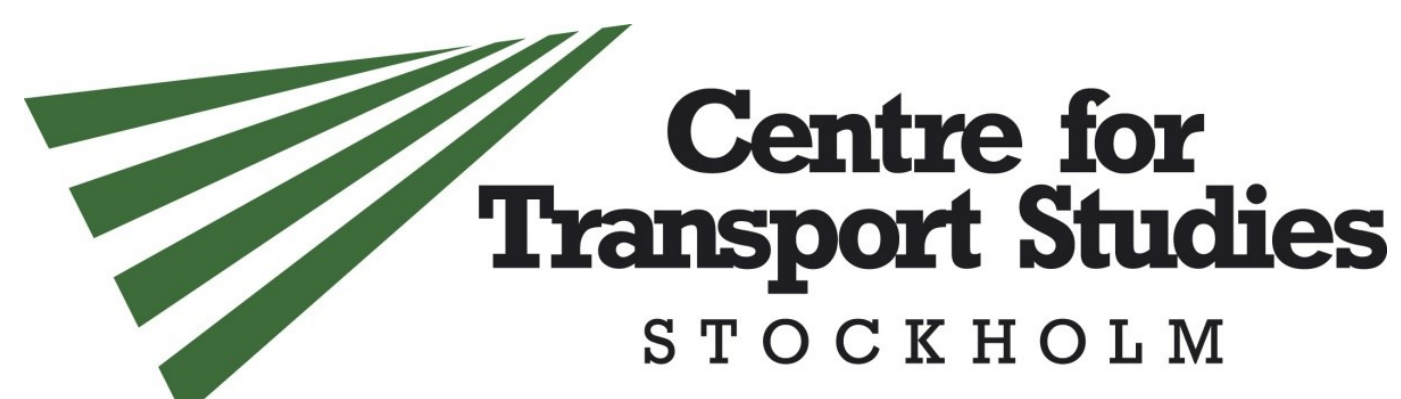

\title{
The Gothenburg congestion charge Effects, design and politics
}

\author{
Maria Börjesson - CTS, KTH Royal Institute of Technology \\ Ida Kristoffersson - CTS, Sweco
}

CTS Working Paper 2014:25

\begin{abstract}
This paper summarizes the traffic effects of the Gothenburg congestion charges introduced in 2013. The system is similar to the system introduced in Stockholm in 2006; both are designed as time-of-day dependent cordon pricing systems. We find that many effects and adaptation strategies are similar to those found in Stockholm, indicating a high transferability between smaller and larger cities with substantial differences in public transport use. However, there are also important differences regarding some of the effects, the accuracy of the model forecasts and public support arising from different topologies, public transport use, congestion levels and marketing of the congestion charges to the public. Finally, the Gothenburg case suggests that whether congestion charges are introduced or not depends on the support among the political parties, and that this is determined primarily by the prevailing institutional setting and power over revenues, and to a lower extent by the public support, and benefits from congestion reduction.
\end{abstract}

Keywords: Congestion charges; Behavioural adaptation; Time-dependent cordon; Tolling system; Traffic effects; Public support; Transferability; System Design

JEL Codes: R41, R42, R48

Centre for Transport Studies

SE-100 44 Stockholm

Sweden

www.cts.kth.se 


\section{INTRODUCTION}

Gothenburg, the second largest city in Sweden, introduced a time-of-day dependent cordon-based congestion charging scheme in January 2013. There are only a few cities in the world that have previously introduced congestion charges. ${ }^{1}$ In particular, analyses of traffic effects have only been published for the congestion charging systems in Singapore (Olszewski and Xie, 2005; Phang and Toh, 1997), London (Santos, 2005; Santos and Shaffer, 2004), Stockholm (Börjesson et al., 2012; Eliasson et al., 2009) and Milan (Carnovale and Gibson, 2013).

The Gothenburg system resembles the Stockholm system in many ways. However, the evaluation of the Gothenburg charges contributes to the literature because Gothenburg differs considerably from the cities where traffic effects of congestion charges have previously been evaluated in terms of size, public transport share and congestion levels. The justification for and marketing of the congestion charges also differs between the cities. Gothenburg is a small city (500 000 inhabitants), where congestion is limited to a few highway junctions. The share of public transport trips in the charged relations is substantially lower than in Stockholm, London and Singapore. The implication of the comparatively low public transport share is of particular interest, since this is often assumed to be a key factor for both effectiveness and public support for congestion charges (Santos, 2005).

This paper evaluates the traffic effects of the Gothenburg charges, and compares them to the transport model predictions and political targets. We consider effects on traffic volumes and travel times, as well as adaptation mechanisms and support issues. Based on differences and similarities between Gothenburg and Stockholm, we also draw lessons relating to transferability of traffic effects, adaptation strategies, system design, and public support. This provides some indication of the transferability between cities.

Santos et al. (2008) suggest that the main reason that there are so few examples of congestion charging schemes in the world is lack of public support, implying low political support (i.e. support for congestion charges among political parties). What is striking in the Gothenburg case, therefore, is that congestion charges were introduced despite low public support. We draw lessons regarding the role of the prevailing institutional setting, which shapes the political support, in the process leading to the introduction of congestion charges.

The Gothenburg congestion charges followed the Stockholm charges introduced in 2006. The Stockholm charges did not pave the way for the Gothenburg charges by increasing public support, but by influencing the distribution of national transport investment grants. In a stroke this altered the political support to the extent that all political parties in the city council of Gothenburg became in favour

${ }^{1}$ Other types of road pricing systems exist in many places in the world, e.g. financing road tolls or other tolling systems used as a fiscal policy to raise revenue, such as Oslo and Bergen, and HOT-lanes on US motorways. 
of congestion charges. The key factor for receiving political support for charging in Stockholm was an agreement with the national government that Stockholm would receive a major infrastructure package, funded by the congestion charging revenue leveraged with an equally large national grant. This agreement inspired the Gothenburg politicians to strike a similar deal, co-funding a large infrastructure package with revenues from congestion charges. A consultative referendum was held in September 2014, where 57 percent voted against congestion charges, although the support did increase after introduction of the charges just as in Stockholm (Eliasson, 2014). Since then the Gothenburg city council has decided to keep the charges in spite of the referendum result.

Raising revenue is thus the primary objective of the charges, which make them similar to the tolling schemes in the Norwegian cities (Ieromonachou et al., 2006; Larsen and Østmoe, 2001). According to the deal, the system should generate yearly revenues of 90 million EUR ${ }^{2}$. Given this revenue target, a secondary design objective is to reduce congestion. According to Swedish legislation, congestion charging systems must be designed to reduce road congestion. The time-of-day dependent charge is therefore located on the bottleneck links. Evenings, nights, weekends and holidays remain free of charge. A third objective is to reduce emissions from cars.

We find that traffic across the cordon was reduced by $12 \%$ during the charged hours and that travel times were reduced in the bottlenecks. Travel time savings in the system are still limited because the average travel time on these links is only approximately five minutes in the morning peak. Despite the lower public transport shares, the adaptation strategies are very similar to those in Stockholm, indicating a high transferability of the effects of the charges between cities with different levels of congestion, as suggested by Börjesson et al. (2014).

The comparatively low use of public transport, characteristic of many small cities, implies that a substantially larger share of the drivers in Gothenburg, compared to Stockholm, pay congestion charges regularly and are negatively affected. Moreover, the benefits from congestion reduction are small. These are likely key reasons for the low public support. Another potential reason for the low support is that decision makers did not manage to frame the congestion charges as a green and therefore morally good measure (Eliasson, 2014) as much as they wanted. The real reason --to collect taxes to be spent on an infrastructure package-- agreed among a large number of political parties and stakeholders in the West Swedish Agreement, was probably seen through by the public. The largest investment in the package is an unbeneficial rail tunnel under Gothenburg (BCR being 0.45 (Mellin et al., 2011)). Although lacking further evidence, the heated public debate regarding the rail tunnel suggests that its low benefits, compared to its costs, have reduced support for congestion charges further.

The Gothenburg case challenges the notion that a focus on revenue recycling and infrastructure investments packages (Goodwin, 1989; Jones, 1991; King et al.,

${ }^{2}$ We have throughout this paper converted SEK to Euro using a conversion rate of 10 SEK/€. 
2007) increases public support for congestion charging. The commitment problem, that the revenue might be diverted to other projects than promised, as suggested by Manville and King (2013), is not a likely problem in Gothenburg. Rather, the Gothenburg case supports the conclusion by Larsen and Østmoe (2001), that earmarking congestion charging for infrastructure induces a risk of realizing dubious projects that produce small benefits to the travellers and are difficult to modify, since they are included in a package deal. Possibly it also stimulates over-investments in infrastructure.

Finally, the Gothenburg case demonstrates that introduction of congestion charges depends not only, or even primarily, on the public support and benefit from congestion reduction, but also on the political support, which is determined by different factors such as the institutional setting. The importance of both public and political support may explain why many cities have not introduced congestion charges in spite of high congestion levels (Edinburgh, Manchester, Helsinki, Copenhagen and New York). In New York, $67 \%$ of the public even supported the proposed charges (Schaller, 2010).

This paper is organized as follows. Section 2 describes the design of the charging system in Gothenburg. Section 3 presents effects on traffic volumes and travel times and how they compare to model forecasts. Section 3 also describes the drivers' adaptation strategies. Section 4 compares revenues to the target and discusses system costs. The political process leading up to introduction of congestion charges is described in Section 5. Section 6 concludes the paper.

\section{DESIGN}

Three objectives for the congestion charge were stated: raising revenues for the investments in the West Swedish Agreement, reducing congestion and improving the environment. No congestion reduction target was quantified, however. Many stakeholders initially seemed to have the idea that it would be easy to copy the system design from Stockholm and set up a cordon around the inner city of Gothenburg. Designing a real-world congestion charging system, however, is a difficult task and the design must be adapted to the local conditions. An important difference between the cities is that in Gothenburg, the bottlenecks are not located on arterials leading to and from the inner city, but rather on arterials leading to the hub of the highway system, to the north of the inner city; see Figure 1.

Other differences are that Gothenburg is less than half the size of Stockholm and that Gothenburg has limited congestion and a lower public transport market share. In Gothenburg, the public transport market share in 2012 was $26 \%$ for commuting trips in the relations where the charges apply (Björklind et al., 2014). In Stockholm, the corresponding market share is $77 \%$ (SL, 2013). A key factor for the lower public transport market share in Gothenburg is that the population density of the Gothenburg region is lower and that many workplaces are not located in the city centre. The public transport system consists of mainly trams and buses. 
Without a careful analysis using a transport model that takes local conditions into account, it is very easy to design a system that creates more problems than it solves, by shifting congestion to other parts of the network or by initiating barriers or rat-running within residential areas. The national forecasting model Sampers (Beser Hugosson and Algers, 2002) was applied when designing the system. It was also used to design the Stockholm system.

Sampers consists of nested logit models for six trip purposes (Work, School, Business, Recreation, Social and Others), modelling choices of trip frequency, destination and mode (car as driver, car as passenger, public transport, walk and cycle). The demand models include private and business travel. Freight traffic OD matrixes are fixed (and thus assumed to be insensitive to congestion charge). There are three analysed time periods (morning peak, evening peak and off peak), over which demand is distributed using fixed time period factors per trip purpose applied uniformly to all origin-destination pairs. Road and transit link flows are calculated using the software package EMME/3 (INRO Consultants Inc., 2010).

The topography of Gothenburg complicates the design of the system, and induces more unwanted side effects than in Stockholm. The Stockholm cordon, surrounding the inner city (where the bottlenecks are located) cuts through the water. The water works as a natural border, preventing the cordon from inducing undesirable barriers and route choice effects. In Gothenburg, however, there are no such natural barriers, and in particular not where the bottlenecks and the cordon are located, causing unpopular barriers within residential areas. The lack of natural barriers also implies that the number of checkpoints has to be larger than in Stockholm (38 compared to 18 in Stockholm), in order to avoid rat-running within residential areas.

The final scheme consists of a circle cordon with two antlers (see Figure 1). Charges are time-dependent and levied 6:00-18:30 on weekdays, ranging from 8 SEK to 18 SEK. Vehicles are charged when crossing the cordon in both directions. A multi-passage rule states that if passing the cordon more than once within 60 minutes, only the highest charge has to be paid. The maximum cost for a day is 60 SEK. The system uses the same technology as in Stockholm (ANPR). 


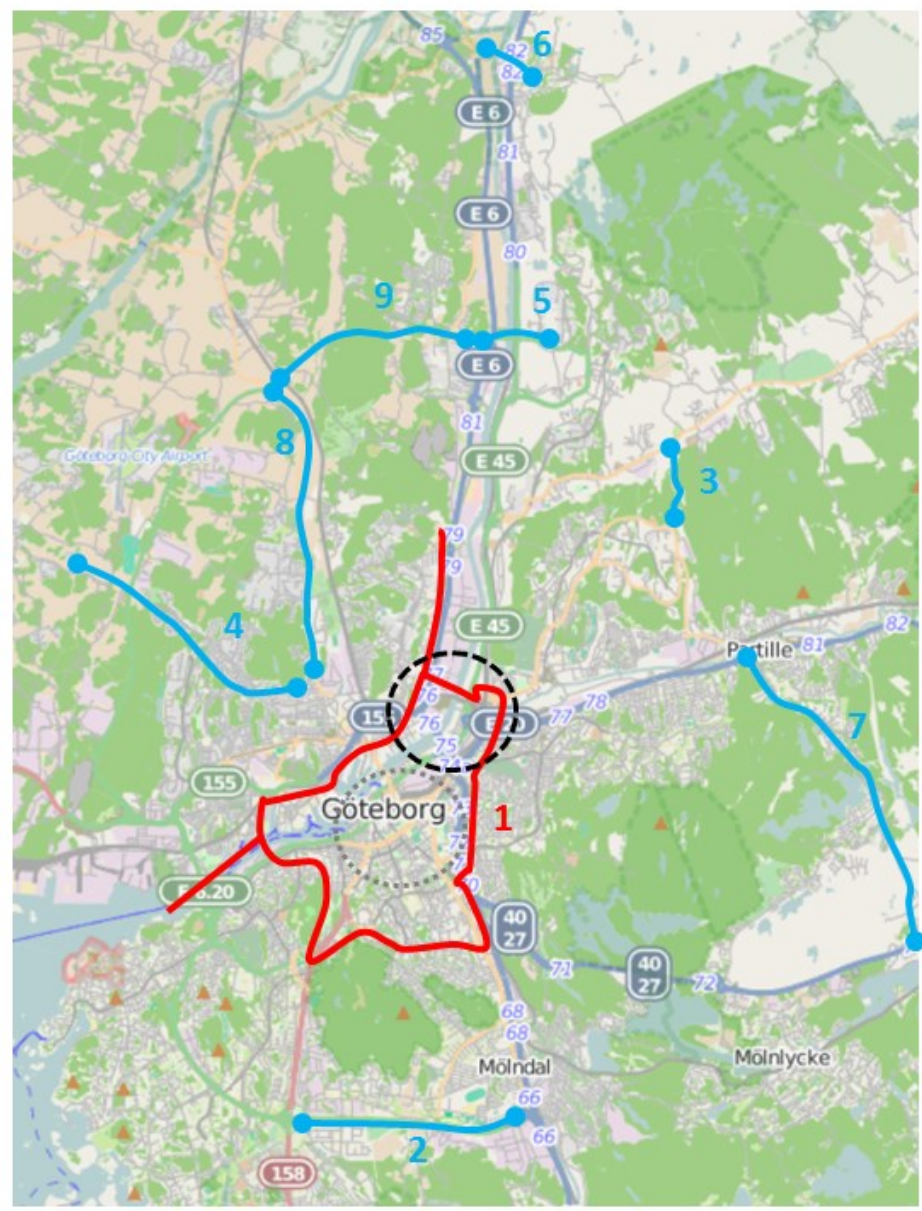
1. Charging Cordon
2. Söderleden
3. Bergsjövägen
4. Björlandavägen
5. Angeredsbron
6. Jordfallsbron
7. Landvettervägen
8. Tuvevägen
9. Norrleden

\begin{tabular}{|l|r|}
\hline Time (weekdays) & Charge \\
\hline $06: 00-06: 29$ & $8 \mathrm{kr}$ \\
\hline $06: 30-06: 59$ & $13 \mathrm{kr}$ \\
\hline $07: 00-07: 59$ & $18 \mathrm{kr}$ \\
\hline $08: 00-08: 29$ & $13 \mathrm{kr}$ \\
\hline $08: 30-14: 59$ & $8 \mathrm{kr}$ \\
\hline $15: 00-15: 29$ & $13 \mathrm{kr}$ \\
\hline $15: 30-16: 59$ & $18 \mathrm{kr}$ \\
\hline $17: 00-17: 59$ & $13 \mathrm{kr}$ \\
\hline $18: 00-18: 29$ & $8 \mathrm{kr}$ \\
\hline $18: 30-05: 59$ & $0 \mathrm{kr}$ \\
\hline
\end{tabular}

Figure 1: Gothenburg with the toll cordon (1), the circumferential roads where traffic increases were anticipated (2-9), and the time-of-day dependent charge levels. The highway hub where the main bottlenecks are located is depicted with a dashed circle and the inner city with a dotted circle.

\section{EFFECTS OF THE CHARGES}

\subsection{Traffic volume}

\section{Traffic volume across the cordon}

The reduction in traffic volume across the cordon during charged hours stabilized at $12 \%$ after approximately eight months (Figure 2 ). The adjustment was slower in Gothenburg than in Stockholm, where the effect on the traffic volume across the cordon stabilized already after one month (Eliasson et al., 2009). 


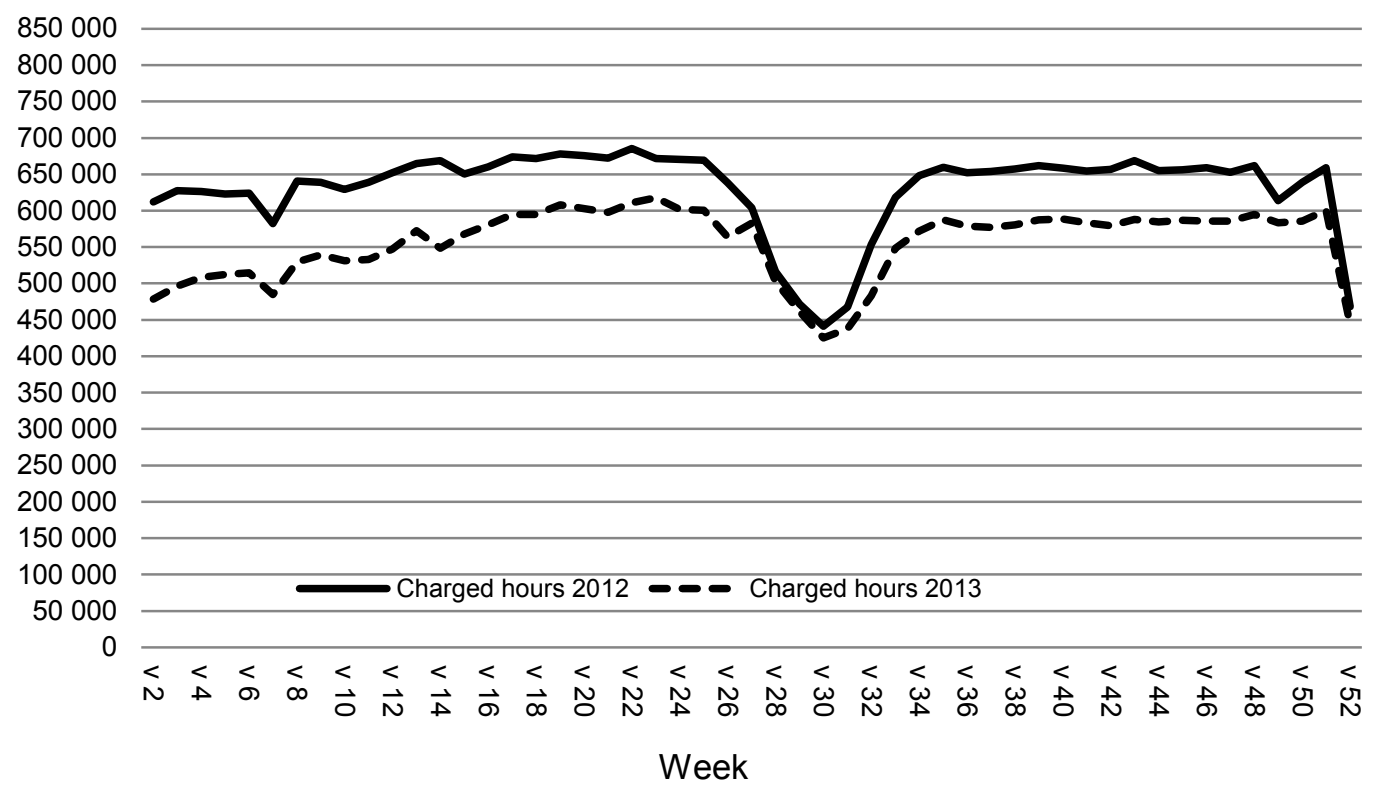

Figure 2: The number of vehicles passing the cordon during charged hours (weekdays 6:00-18:30) with and without congestion charging.

Table 1 and Figure 3 show that the reduction in traffic volume over the cordon remains reasonably constant throughout the charged time period, although the charge varies. The reduction is just slightly larger in the morning peak. Outside the charged hours the traffic volume remains largely unchanged. There is just a small reduction in the evening, presumably because these trips would have been charged in the morning going in the other direction. Spikes in the traffic volume in the morning and evening, just before and after the charge increases or decreases, indicate small shifts in departure time. Similar spikes were observed in Stockholm in the first years after the introduction (Kristoffersson, 2013), but vanished later. Otherwise, there are no clear signs of departure time shifts.

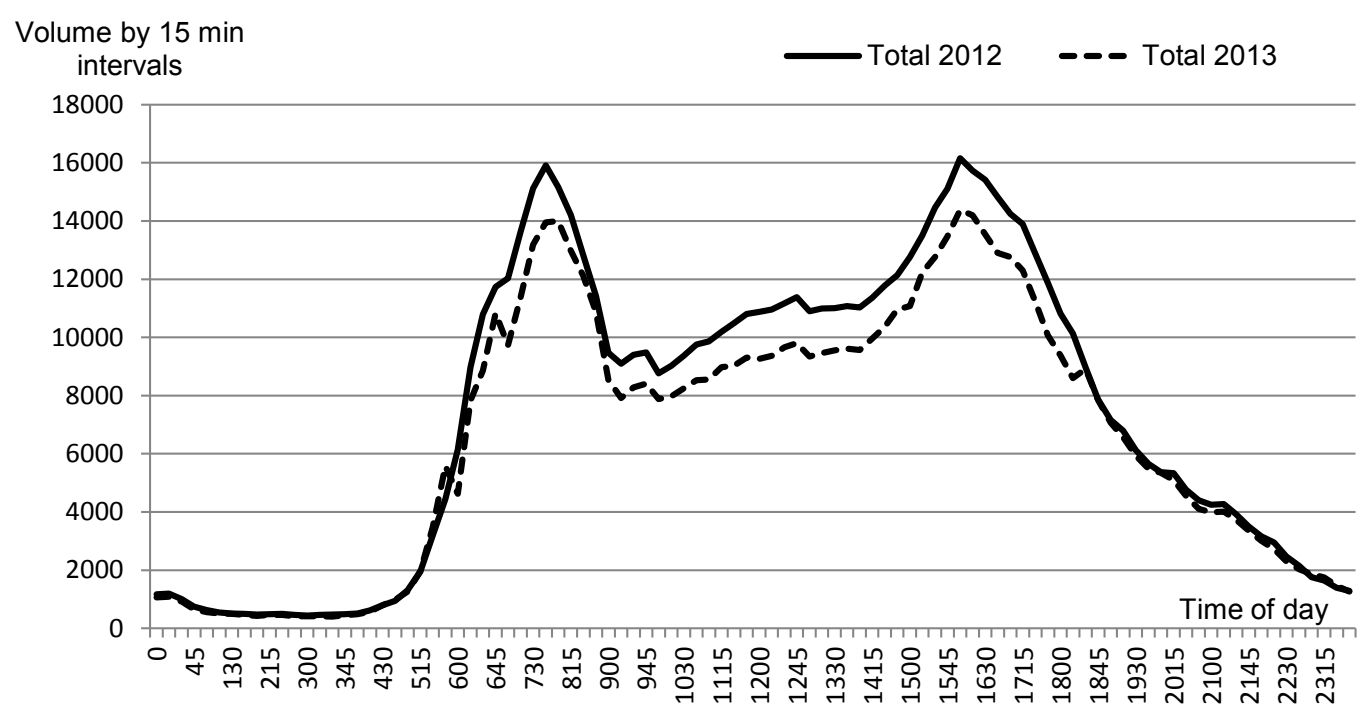

Figure 3: Traffic volume over the cordon by 15 min intervals 
Figure 4 points to substantial differences in reduction of traffic volumes across the 38 checkpoints, ranging from approximately $-30 \%$ to $+8 \%$. The increase in traffic volume at two checkpoints indicates some route choice effects.

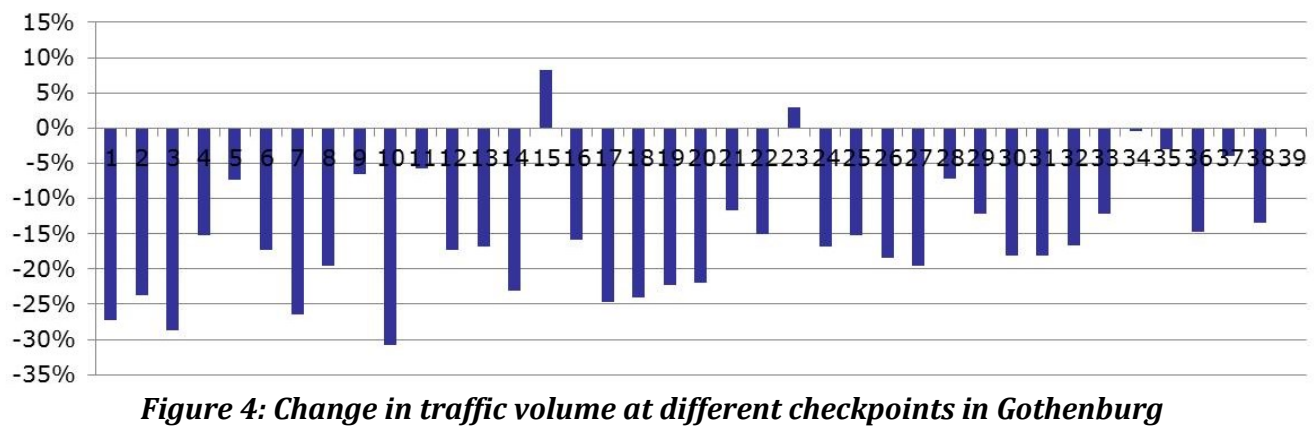

Table 1 also compares the observed reduction in traffic volume across the cordon to the model predictions. The traffic reduction in the peak is overpredicted while it is close to the observed in the off-peak. A striking pattern is that the transport model predicts a smaller reduction during off-peak hours (when the charge is lower) than during peak hours, while the observed effect remains constant over the charged hours. The predictions and observed effects in Stockholm showed the same pattern. One difference, however, is that in Stockholm the prediction of the peak effect was similar to the observed outcome while the effect was underpredicted in the off-peak (Eliasson et al., 2013). The latter was due to underprediction of the effect on discretionary trips, which constitute the bulk of off-peak traffic.

Both in Stockholm and Gothenburg, the discretionary travellers adapted in more heterogeneous ways (see further Section 3.3) than commuters (who mainly shifted travel mode). The adaptation mechanisms applying to discretionary trips could therefore be more difficult to model, explaining why the effect on these trips was underestimated in Stockholm. If, which seems probable, this also applies to Gothenburg, the off-peak predictions are accurate because an underprediction of the off-peak effect is cancelled out by a general overprediction of the total effect, caused by other factors. These other factors would explain why the effect in the peak-hour is overpredicted: $18 \%$ compared to the observed $13 \%$.

Table 1: Decrease in traffic volume over the cordon for different periods of the day

\begin{tabular}{|l|c|c|}
\hline October 2012 to October $\mathbf{2 0 1 3}$ & Observed & Forecast \\
\hline AM Peak & $-13 \%$ & $-18 \%$ \\
\hline PM Peak & $-12 \%$ & $-18 \%$ \\
\hline Mid-day & $-12 \%$ & $-13 \%$ \\
\hline Charged hours & $-12 \%$ & $-15 \%$ \\
\hline Uncharged hours & $-2 \%$ & $0 \%$ \\
\hline
\end{tabular}

The general overprediction of the total effect is caused by two main factors. First, the model underpredicted the use of the multi-passage rule (described in Section 2). The model predicted that approximately $30 \%$ of the traffic would be 
free of charge due to this rule, whereas the outcome was $45 \%$. Second, the model overpredicted the route choice effects (see further Traffic volume on roads bypassing the city centre). In other words, the model predicted that more drivers than observed would adapt by diverting to circumferential links from the charged links. The effects on the route choice are more difficult to model in Gothenburg than in Stockholm due to a different topology, implying more opportunities to avoid charging by taking a detour.

The overpredictions in route choice could be due to values of time in the assignment model EMME/3 being too low, although these were adjusted upwards in the a priori design and forecast process ${ }^{3}$. They could also be due to travel time savings predicted by the assignment model being too small.

\section{Traffic volume in the city centre}

One of the often mentioned political objectives of congestion charges is lower traffic volumes and better air quality in the city centre; this is also the case in Gothenburg. The size of the traffic reduction in the inner city is assessed on the basis of traffic counts on a selection of representative streets listed in Table 2.

The implementation of congestion charges coincided with other measures aimed at improving the public transport system, primarily by introducing new bus lanes. These measures reduced the capacity for driving and parking in the inner city, and have thus reduced the traffic volume over and above the reduction from congestion charges.

The last row of Table 2 reports average traffic reduction (weighted with volume) across all streets. The average reduction is $9 \%$ during charged hours. During non-charged hours, however, at which the reduction across the cordon is $2 \%$, the average reduction on the city streets is still $6 \%$. These numbers indicate that the measures additional to the congestion charges reduced car traffic by $4-6 \%$, suggesting that the reduction arising from the congestion charges is $3-5 \%$. Because the traffic is only counted on a sample of representative streets, a possible selection bias may induce further uncertainty in this estimate. A reduction in traffic volume within the city of approximately one third of the reduction across the cordon is close to what was observed in Stockholm.

The reduced car traffic volume in the inner city implies that emissions from car traffic, such as nitrogen dioxide $\left(\mathrm{NO}_{2}\right)$ and particles, have been reduced. These reductions, however, have not been observed directly in air quality measurements, mainly due to substantial variation in air quality across years arising from variations in weather conditions.

\footnotetext{
3 The upward adjustment was made because the main factor for the slightly too high predictions of the reduction in the number of vehicles across the cordon before the Stockholm charges were introduced was too low values of time in the transport assignment model EMME/3 (Eliasson et al,2013).
} 
Table 2: Traffic reduction on key inner city streets.

\begin{tabular}{|l|r|r|r|r|l|}
\hline & $\begin{array}{l}\text { Charged } \\
\text { Hours }\end{array}$ & $\begin{array}{l}\text { AM } \\
\text { Peak }\end{array}$ & $\begin{array}{l}\text { PM } \\
\text { Peak }\end{array}$ & Mid-Day & $\begin{array}{l}\text { Non- } \\
\text { Charged } \\
\text { Hours }\end{array}$ \\
\hline Ullevigatan & $-15 \%$ & $-15 \%$ & $-15 \%$ & $-14 \%$ & $-11 \%$ \\
\hline Sten Sturegatan & $-18 \%$ & $-28 \%$ & $-22 \%$ & $-13 \%$ & $-16 \%$ \\
\hline Nya Allén & $-8 \%$ & $-11 \%$ & $-4 \%$ & $-10 \%$ & $1 \%$ \\
\hline Engelbrektsgatan & $1 \%$ & $0 \%$ & $0 \%$ & $3 \%$ & $-2 \%$ \\
\hline Vasagatan & $6 \%$ & $10 \%$ & $14 \%$ & $0 \%$ & $12 \%$ \\
\hline Per Dubbsgatan & $-14 \%$ & $-17 \%$ & $-18 \%$ & $-10 \%$ & $-9 \%$ \\
\hline Eklandagatan & $-6 \%$ & $-8 \%$ & $-7 \%$ & $-5 \%$ & $-5 \%$ \\
\hline Parkgatan & $9 \%$ & $10 \%$ & $10 \%$ & $8 \%$ & $9 \%$ \\
\hline Linnegatan & $-3 \%$ & $-3 \%$ & $2 \%$ & $-4 \%$ & $-4 \%$ \\
\hline Aschebergsgatan & $-16 \%$ & $-17 \%$ & $-18 \%$ & $-14 \%$ & $-12 \%$ \\
\hline Weighted Average & $-9 \%$ & $-11 \%$ & $-10 \%$ & $-8 \%$ & $-6 \%$ \\
\hline
\end{tabular}

\section{Traffic volume on roads bypassing the city centre}

In the design process it became clear that, due to the topology of the transport network, an unavoidable side effect of the charges would be traffic increases on some circumferential roads. The roads where increases were anticipated are depicted in Figure 1.

Table 3 reports observed effects on traffic volumes for these roads, in the morning peak, afternoon peak and mid-day. For some of them the traffic volume increases are substantial: Landvettervägen, Jordfallsbron and Norrleden. While these increases were an unwelcome development for inhabitants living close to these roads, they do have enough capacity to manage the new traffic volumes. The traffic increase in the circumferential roads indicates route choice effect.

The column to the right in Table 3 shows the model-based forecast effect on traffic volumes made before the introduction of the charges. With a few exceptions, which are discussed below, the forecast effect in terms of signs and relative size, are consistent with the outcome. The absolute effect, however, is consistently overpredicted on the circumferential links, indicating that the model overpredicts the effect on route choice as previously discussed.

The traffic has increased substantially on the bridge Jordfallsbron, although the model predicted an unchanged volume. The traffic on this bridge, however, was affected by reconstructions on the adjacent highway E45, finished just when the charges were introduced. The reconstructions explain part of the traffic increase. However, the traffic also increases during the non-charged hours, indicating that the charges do increase the traffic volume slightly, which the model did not predict.

For one of the roads in the table, Björlandavägen the model predicted reductions in traffic volumes. But the model forecast was not trusted in this 
respect and traffic increases were still anticipated. Nevertheless, as depicted by Table 3, the traffic volumes did decrease as predicted. Björlandavägen demonstrates how essential a transport model is for designing and predicting effects of congestion charges. Without a transport model, it is often impossible even for an expert to foresee the final result, even in terms of signs, of many overlapping effects. Hence, although the model predictions are by no means perfect in terms of absolute changes, they are still better than expert judgments.

Table 3: Changes in traffic volume for roads that by-pass the cordon

\begin{tabular}{|l|r|r|r|r|r|r|}
\hline & \multicolumn{3}{|l|}{ Observed } & Forecast \\
\hline & $\begin{array}{l}\text { Charged } \\
\text { Hours }\end{array}$ & $\begin{array}{l}\text { AM } \\
\text { Peak }\end{array}$ & $\begin{array}{l}\text { PM } \\
\text { Peak }\end{array}$ & Mid-Day & $\begin{array}{l}\text { Non-Charged } \\
\text { Hours }\end{array}$ & $\begin{array}{c}\text { AM } \\
\text { Peak }\end{array}$ \\
\hline Söderleden & $1 \%$ & $1 \%$ & $-1 \%$ & $2 \%$ & $3 \%$ & $3 \%$ \\
\hline Bergsjövägen & $6 \%$ & $3 \%$ & $6 \%$ & $7 \%$ & $2 \%$ & $15 \%$ \\
\hline Björlandavägen & $-2 \%$ & $-4 \%$ & $-4 \%$ & $0 \%$ & $4 \%$ & $-8 \%$ \\
\hline Angeredsbron & $4 \%$ & $4 \%$ & $1 \%$ & $8 \%$ & $-1 \%$ & $18 \%$ \\
\hline Jordfallsbron & $20 \%$ & $24 \%$ & $25 \%$ & $14 \%$ & $13 \%$ & $0 \%$ \\
\hline Landvettervägen & $16 \%$ & $19 \%$ & $16 \%$ & $14 \%$ & $2 \%$ & $32 \%$ \\
\hline Tuvevägen & $8 \%$ & $6 \%$ & $8 \%$ & $8 \%$ & $4 \%$ & $22 \%$ \\
\hline Norrleden & $26 \%$ & $26 \%$ & $22 \%$ & $30 \%$ & $0 \%$ & $34 \%$ \\
\hline
\end{tabular}

\subsection{Travel times}

Figure 5 shows the arterial routes and the links where travel times were measured before and after the introduction of congestion charges (City of Gothenburg, 2013a). Travel times were also measured on selected links inside the toll cordon and on the relevant bypasses. ${ }^{4}$ The links where the travel times were measured are sorted into one of the four different categories: inner arterials, outer arterials, inside cordon, and bypasses. Inner arterials are the four innermost links on arterial routes depicted on the map in Figure 5. The category outer arterials includes all other links depicted on the map. Streets inside the cordon and the bypasses on which travel times were measured are not depicted in Figure 5. Their exact location can be found in the travel time report (City of Gothenburg, 2013a).

Figure 6 shows the relative increase in travel times in the morning peak hour 7.00-8.00 compared to the free flow travel time, before and after the introduction of the congestion charges for the four categories of links. The observed travel times are averaged over all weekdays within five weeks in September and October in 2012 (before) and 2013 (after). A relative increase in travel time of $0 \%$ corresponds to the free-flow travel time and $100 \%$ corresponds to a travel time twice the free-flow travel time. 
The error bars in Figure 6 illustrate the average between-day variation in travel time for the six 10-minute intervals within the peak hour 7.00-8.00. The relative increase in travel time for the days when the best and worst decile of the travel time distribution were observed is identified for each six 10-minute interval. The error bars show the best and worst decile, averaged over the six 10-minute invervals within the peak hour 7.00-8.00.

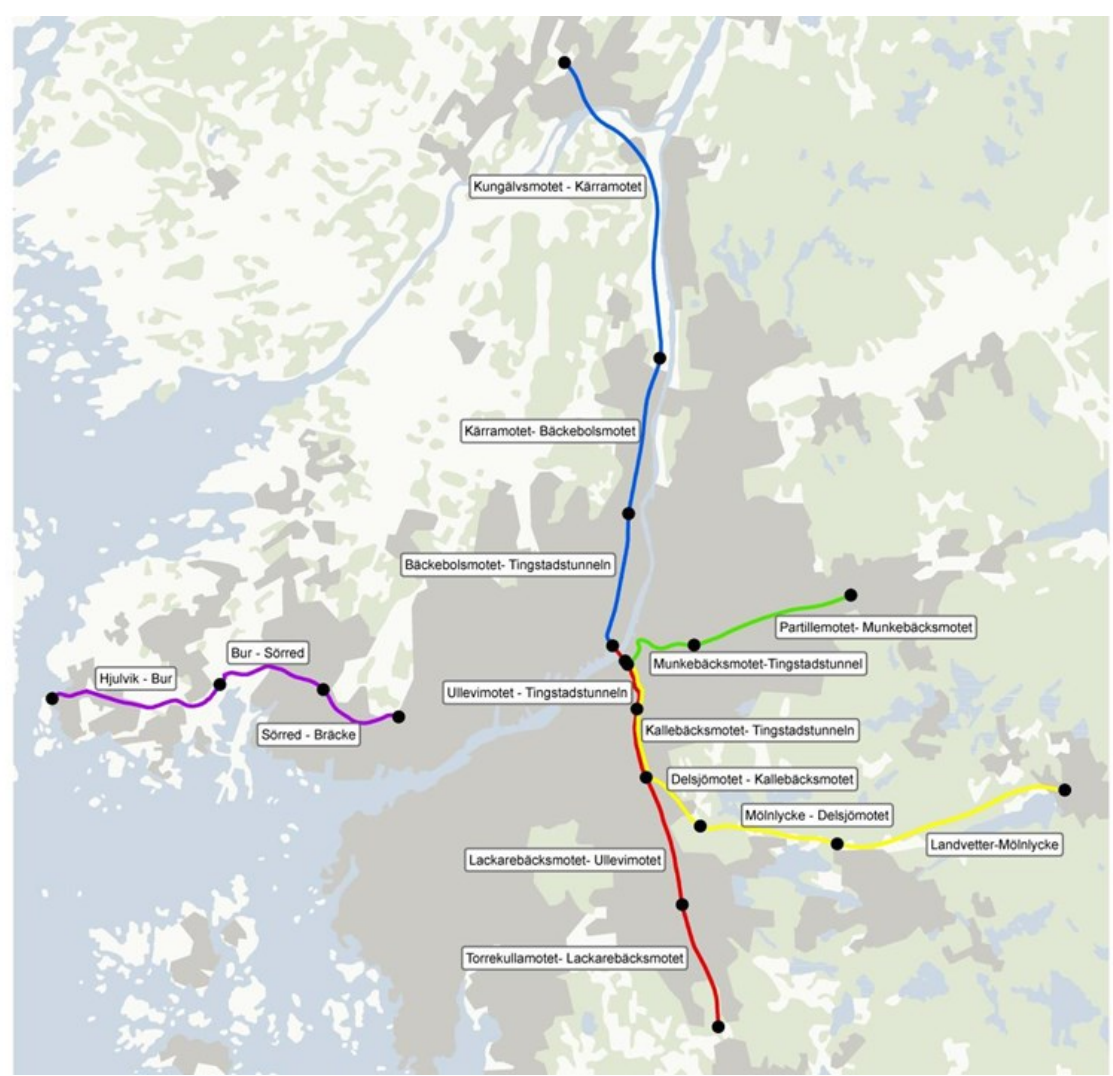

Figure 5: Arterial roads where travel times are observed before and after the introduction of charges. 


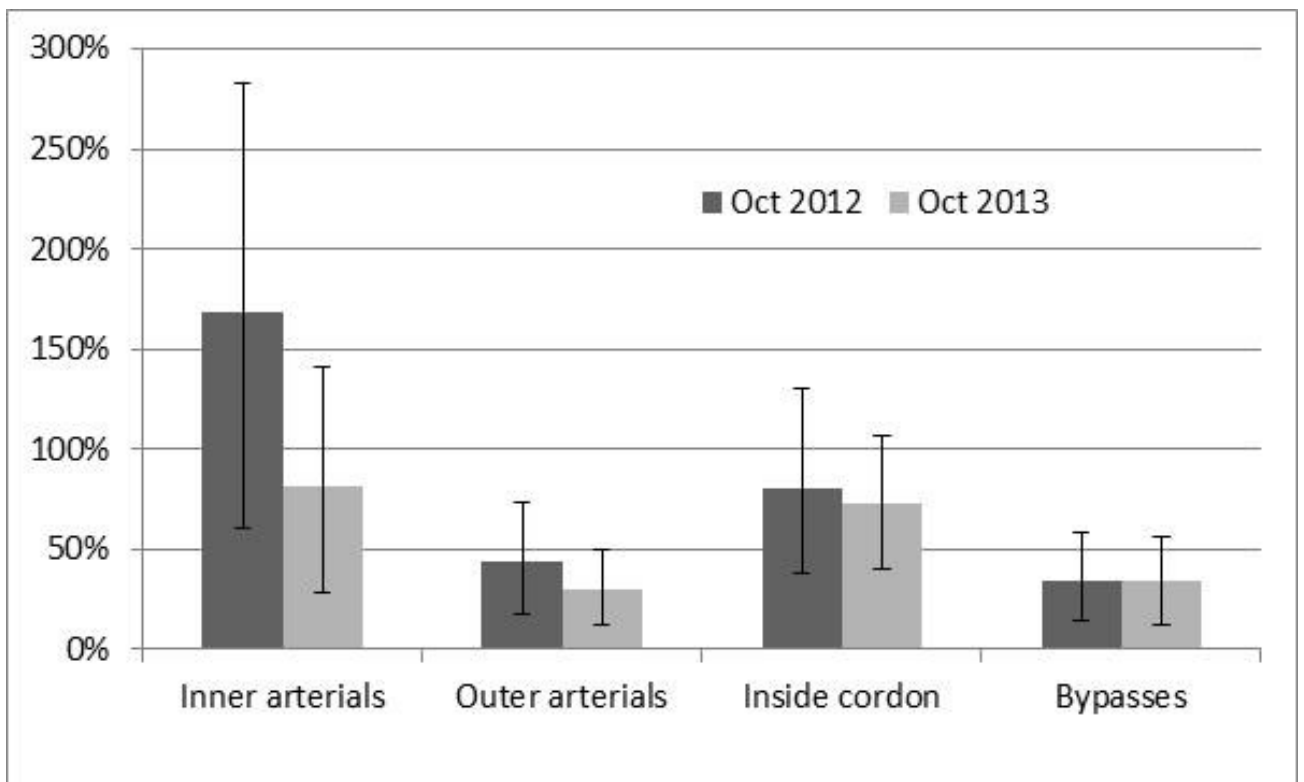

Figure 6: Relative increase in travel time in morning peak hour 7.00-8.00 for different categories of links. The observed travel times are taken from all week days during five weeks in September and October.

Figure 6 shows that prior to charging, congestion was limited to the innermost arterials in the morning peak. Congestion on these links is significantly reduced by the charges. The travel time savings are still limited because the average travel time on these links is only approximately five minutes in the morning peak.

\subsection{Adaptation strategies and increase in public transport}

To analyse adaptation strategies among the drivers priced off the road, a twowave panel travel survey was conducted with 3000 individuals residing across the Gothenburg region in March-April 2012 and in March-April 20135. According to the survey the share of car trips priced off the road was approximately the same for commuting and discretionary trips (City of Gothenburg, 2013b). This is consistent with the finding that the total percentage reduction remained approximately constant over the day (where the bulk of commuters travel in the peak and the bulk of discretionary trip drivers travel in the off peak).

The adaptation strategies, however, differ between commuting and discretionary trips. All commuters priced off the road switched to public transport. Among discretionary travellers the main adaptation strategies are

5 Only individuals with commuting trips in charged relations were selected. The same respondents were approached in both waves. Approximately 3000 individuals responded to the surveys in both years (reporting a total of 17,000 trips from one day per person and year). 
changing destination and reducing trip frequency. The adaptation mechanisms observed in Stockholm are remarkably similar to those observed in Gothenburg, for both commuters and discretionary travellers (Börjesson et al., 2012).

Since the respondents were not sampled randomly and the sample is fairly small, the total increase in public transport trips according to the travel survey is unreliable. Moreover, the traffic counts for the Gothenburg public transport system are unreliable because it is optional to tap the travel card when entering buses and trams for travellers with yearly or monthly tickets, which are in the majority. To assess how the public transport travel volume has changed, the most reliable data source is therefore ticket sales.

Since it is mainly commuters who switch to public transport, and they almost exclusively use monthly and yearly tickets, we only regard the sales of monthly and yearly tickets. The price of single tickets changed substantially between 2012 and 2013, so single ticket sales are not comparable between the years. The monthly and yearly ticket sales increased by 7.5 percent. This number corresponds relatively well to the estimate based on the two-wave travel survey; according to this, the public transport trips increases by 6 percent in charged relations.

However, the sales of monthly and yearly tickets increased by around 2 percent (between 1-3 percent) yearly over several years prior to 2012, due to population growth and various marketing campaigns (both continuing during 2013). Together these numbers suggest that the increase in public transport use due to the congestion charges is within the range of 4.5 and 6.5 percent. The model predicted a slightly lower increase in public transport trips: 3 percent within the greater Gothenburg region.

\section{REVENUES AND SYSTEM COSTS}

The congestion charges in Gothenburg generated a gross revenue of 71 million EUR during its first year. This is close to the 76 million EUR generated by the Stockholm system in 2013, although Gothenburg is less than half the size of Stockholm and the charged amounts are lower. This implies that a considerably larger proportion of the population of Gothenburg, compared to Stockholm, pays congestion charges. One of the main reasons is that the share of public transport trips is lower than in Stockholm (as discussed in Section 2), partly due to a different land-use pattern.

The revenue of 71 million EUR is lower than the Sampers forecast from 2009, which predicted a gross revenue of 93 million EUR (Björklind et al., 2014). There are two main reasons for the underprediction of revenues. First, the analysts made the assumption that the traffic across the cordon would increase by $1.2 \%$ per year $2008-2013$. Due to the sharp increase in fuel prices and the economic downturn in this period, however, the traffic decreased by on average $0.7 \%$ per year. Second, the multi-passage rule resulted in more uncharged passages, as discussed in Section 3.1. 
The operating cost of the system, including costs for maintaining the technical system, customer service and invoicing, is approximately 0.2 EUR per charged passage (Transportstyrelsen, 2014). In total 62 million passages were charged in 2013, implying a system cost of 12.4 million EUR per year. This corresponds to $17 \%$ of the revenues.

\section{THE PROCESS}

\subsection{The political process}

Before congestion charges were introduced in Stockholm in 2006, the support was as low among political parties in both Stockholm and Gothenburg, as among politicians in most other cities around the world. In less than ten years, however, congestion charges have become completely uncontroversial and accepted by all political parties in Stockholm and by all well-established political parties in Gothenburg. This is not primarily due to the increased public support in Stockholm, but rather because congestion charging has come to play a key role in the negotiations of the national grants for transport investments.

Prior to the Stockholm charges, the local and regional politicians of Stockholm of all parties were greatly concerned that Stockholm would receive fewer national infrastructure grants if they introduced congestion charges. They feared that Stockholm would be forced to use the revenues from the congestion charges and thereby miss out on national grants. This issue was solved by an agreement between the national government and the region settled in late 2007, according to which Stockholm would receive a major transport investment package, 50 percent funded by the revenues and 50 percent by the national government. This was a turning point for the political support, and since then all political parties in Stockholm have been in favour of the charges.

Before the Stockholm agreement was settled, most of the major transport investments in Sweden were funded by national grants. But at the outset of the preparation of the national investment plan 2010-2021, the Government declared that investments receiving regional co-funding would be prioritized, as well as cost efficient investments and investments in urban regions. The Transport Administration handed over a proposal for the national investment plan to the Government on 1 September 2009. Local and regional politicians in Gothenburg, however, felt that their region, in spite of being the second largest city in Sweden, did not receive their fair share of the national infrastructure grants. In particular, they argued, they were given substantially less than the Stockholm region.

In the spring of 2009 a small group representing the national Government, the regional governments (Region Västra Götaland and Region Halland), the Gothenburg Region Association of Local Authorities $\left(\mathrm{GR}^{6}\right)$, and the the local government of the City of Gothenburg begun negotiating an infrastructure package, to be co-funded by the region and thereby squeezed into the plan at the

${ }^{6}$ A co-operative organization uniting thirteen municipalities in western Sweden 
last minute. This process, involving a small number of negotiators from each the stakeholders, was informal, closed and lacked authoritative or official instructions. The outcome of these unofficial negations was announced in late August 2009. It resulted in a broad political coalition in the Gothenburg City Council stating its support for a West Swedish Agreement, partly funded by congestion charges (October 28, 2009).

The largest investment in the package is the West Link (2.0 billion EUR), which is an 8-km-long rail link including a 6-km-long tunnel under central Gothenburg. The package also includes a 0.4 billion EUR road tunnel and 0.5 billion EUR for public transport improvements introduced jointly with, or shortly after, the charges. The latter are used to strengthen existing bus and commuter train lines with increased service frequency and separate bus lanes.

The total budget of the Agreement is 3.4 billion EUR, of which 1.7 billion is accounted for by the national Government, 1.4 billion by revenue from the charges (of which 33 percent are paid by citizens in the city of Gothenburg), 0.125 billion by the City of Gothenburg, 0.1 billion by the regions surrounding Gothenburg $^{7}$ and 0.75 billion by realization of increased land values.

The Government planned to establish the national plan in early spring 2010. In order to include, at the last moment, the investments in the West Swedish Agreement, a proposal for the system design and a revenue forecast were required by then. The design process was thus subject to severe time pressure. It started in late August 2009, and was undertaken by a specially formed unit at the national Transport Administration. One of the authors of this paper was participating in this process as expert advisor.

Due to the time pressure, the political constraints regarding the design were not clear at the outset of the design process, slowing the process down. ${ }^{8}$ Although many different designs were investigated and most of them rejected because they caused more problems in the transport system than they solved (see further Section 2), the national parliament had accepted a charging scheme within nine months. ${ }^{9}$ At the expense of some other projects previously included in the proposed plan, the West Swedish Agreement was included in the final national plan adopted by the Government on 1 April 2010.

In the hurried and informal negotiation process, the stakeholders suggested investments that were not properly evaluated. When at a later stage they were evaluated, it became clear that the cost efficiency of the West Link was very low, the BCR being 0.45 (Mellin et al., 2011). The Swedish National Audit Office has criticized the economic efficiency of the West Link in several reports (Riksrevisionen, 2012). However, because this Agreement was negotiated

\footnotetext{
7 Västra Götalands and Hallands län.

${ }^{8}$ For instance, at first a flat-rate charge was suggested, but this was rejected by the national Government, since according to legislation the system must be designed to reduce congestion. ${ }^{9}$ According to the Swedish congestion tax legislation, only the national parliament can make a decision to collect congestion tax.
} 
between many stakeholders and political parties, it could not be modified. This illustrates the problems associated with large infrastructure packages having broad political support, in particular when resulting from hurried and closed negotiations. This has been discussed in the context of the Norwegian road tolls, primarily used to finance large infrastructure investments (Ieromonachou et al., 2006; Larsen and Østmoe, 2001).

There may be several reasons why investments with low cost efficiency were suggested in the first place. One possible reason is that it is difficult to assess the benefit of an investment without a proper evaluation. Another potential reason is that each stakeholder takes the total benefit of an investment into account but only factors in its own share of the cost. For instance, the City of Gothenburg carries only 4 percent of the total cost of the Agreement ( 0.125 out of 3.4 billion EUR). ${ }^{10}$ The politicians in the City Council are thus likely to consider the total benefits of the Agreement but only a small share of its cost.

A further problem recognized by the National Audit Office is that for the capacity of the West Link to be realized, additional investments are needed, roughly corresponding to the cost estimate for the tunnel itself. Hence, in the current CBA, all benefits are included but only approximately half its costs.

\subsection{Referendum 2014}

All political assemblies concerned were involved in this hurried and informal process, albeit most of them at a late stage. However, there was a huge information and communication deficit to the public during this process, and no public involvement. This had consequences in the election of 2010, to the extent that a new political party, Vägvalet, was elected into the City Council of Gothenburg, resistance to the congestion charge being its single issue.

The public resistance resulted in a petition for a referendum, arranged by the tabloid Göteborgs-Tidningen, which was signed by 57,000 citizens of the City of Gothenburg. This petition triggered a decision in the City Council (5 September 2013) to arrange a consultative referendum in conjunction with the general election on 14 September 2014, although several parties, including the Social Democrats, were against it. The question in the referendum was formulated as: "Do you think that the congestion tax should continue after the 2014 election?". Fifty-seven percent of the population voted "No". The referendum was only consultative and the Social Democrats, presently in power in the City Council in coalition with other parties against arranging a referendum, have decided to ignore the result and keep the charges.

A key question is then why the referendum in Stockholm resulted in a majority in favour of the charges while the result of the referendum in Gothenburg was the opposite. The support for congestion charges has always been lower in Gothenburg than in Stockholm, presumably due to the lower public transport shares and lower congestion levels, implying that a larger share of the

10 The City of Gothenburg carries 17 percent of the cost if the third of the charge revenue paid by the citizens of Gothenburg is included. 
population is negatively affected by charges and that fewer drivers receive any significant benefits in terms of travel time reductions (as is shown later in this paper). A further key difference between the cities is that in Gothenburg the charges are marketed and justified mainly as a tax collection instrument needed to finance an investment package, which was not the case in Stockholm.

As in Stockholm (Börjesson et al., 2012) and Edinburgh (Saunders, 2005), the support for the charges dipped just before their introduction, but increased thereafter (see Figure 7: Public attitudes towards the charges and the West Link. The question was formulated as: "How positive or negative are you to the package as a whole?", "Congestion Charging - part of the financing of the other parts of the package?" and "the West Link?", respectively.). The poll in the spring of 2014 still showed a small majority for "No" to congestion charges. However, the respondents in this poll were sampled from the 49 municipalities within the Västra Götaland County. The inhabitants of central Gothenburg are considerably more positive than the residents in the rest of the region (Börjesson et al., 2014). ${ }^{11}$ A majority voting in favour of the charges was therefore expected in the referendum, given that only residents of the city of Gothenburg had the right to vote. The negative referendum result thus give some indication that the opinion declined over the summer in the run-up to the referendum in September, as the public debate increasingly focused on arguments for and against the West Link, strengthening the framing of the congestion charges as a tax collection instrument rather than as something good in itself.

Figure 7 also shows how the attitudes towards the West Link have evolved over time. The positive attitudes to the West Link dropped over the summer in 2012, which could be due to the intense media debate questioning its benefits, costs and cost efficiency just after the criticism from the National Audit Office. This is consistent with the conclusion that the focus on spending revenues on infrastructure investments did not build public support for the charges. According to the survey question (in which the financing of the West Link in not mentioned), $70 \%$ are still in favour of the West Link, but this is a difficult to interpret since less than $40 \%$ are in favour of the charges as a means to financing it. One interpretation is that a clear majority is in favour of the West Link if the national government finance it, but substantially fewer if the Gothenburg region has to finance it.

\footnotetext{
11 Moreover, the referendum result shows that there is a clear majority in favour of the charges in the city centre of Gothenburg, but a clear majority against them outside the city centre: http://www.gp.se/nyheter/val2014/val/1.2490122-trangselskatten-drar-isar-goteborg
} 


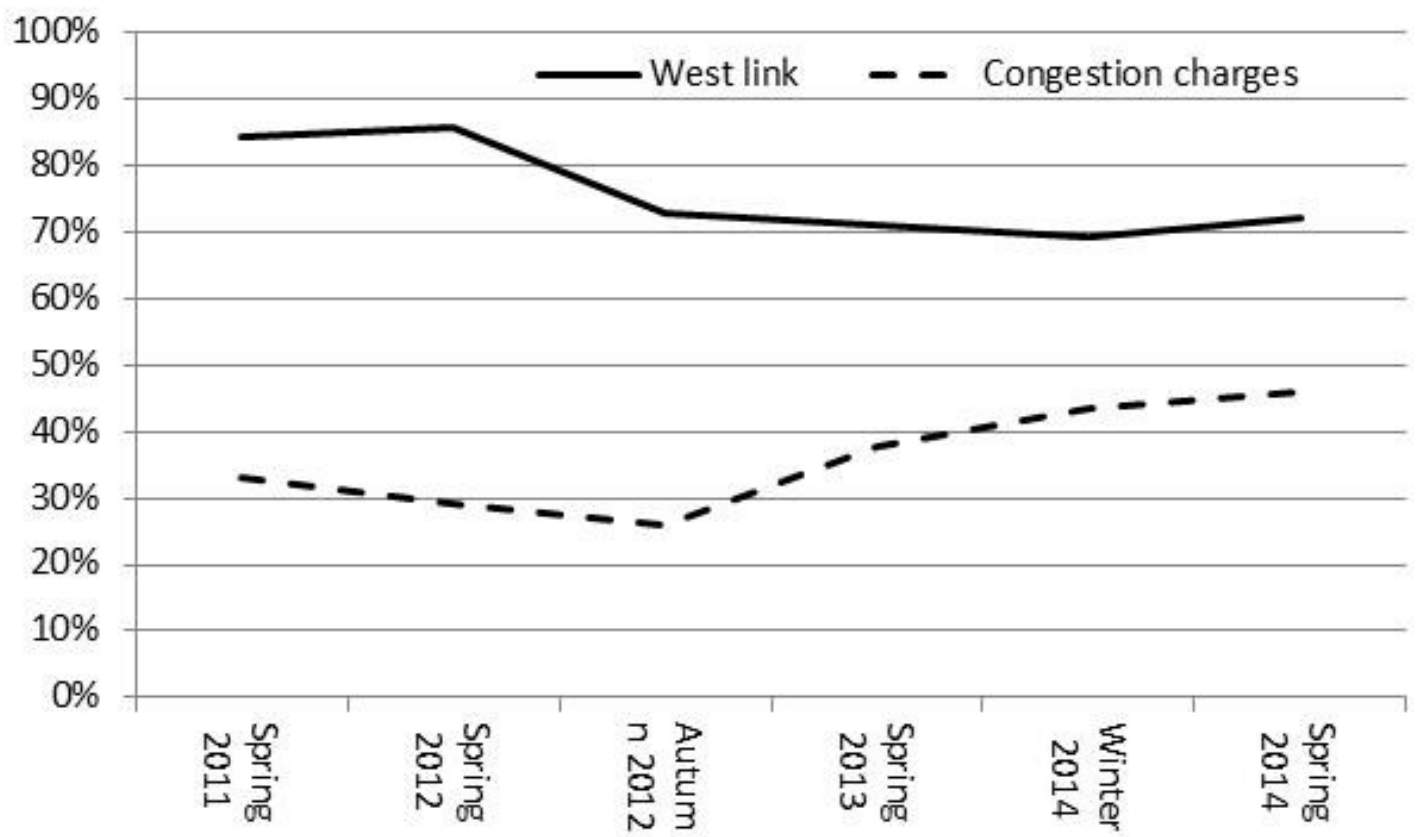

Figure 7: Public attitudes towards the charges and the West Link. The question was formulated as: "How positive or negative are you to the package as a whole?", "Congestion Charging - part of the financing of the other parts of the package?" and "the West Link?", respectively.

\section{CONCLUSIONS}

This paper explores the traffic effects of the Gothenburg congestion charges. It contributes to the literature on ex-post evaluations of congestion charges, because Gothenburg is smaller and has a substantially lower public transport level than other cities where congestion charges have previously been evaluated.

As observed in the bigger cities with congestion charges, we find that the Gothenburg charges are effective in reducing traffic volumes. The reduction across the cordon is 12\% during the charged hours. Many of the findings regarding adaptation mechanisms show the same patterns as those observed in Stockholm, in spite of the lower public transport share. Commuters priced off the road are switching to public transport but discretionary travellers adapt in other ways, mainly by reducing travel frequency and changing destinations. In spite of lower charges in the off peak hours, a constant percentage reduction over the charged hours indicates a higher price elasticity in discretionary trips. It also indicates that the effect on departure time choice is fairly small, at least on the aggregate level. The reduction of car traffic within the city is approximately one third of the reduction across the cordon. These findings are all remarkably similar to findings from Stockholm (Eliasson et al., 2009), indicating high transferability.

However, there are also important differences between Gothenburg and Stockholm arising from the lower public transport shares, lower congestion levels, a different topology and differences in the marketing of the congestion charge to the public. The differences in topology demonstrate the importance of 
adapting the system design to local characteristics of each city. Many stakeholders initially had the idea that it would be easy to copy the system design from Stockholm, but an important difference between the cities is that the bottlenecks are not located on arterials leading to and from the inner city of Gothenburg. Due to the topology of Gothenburg, there are also larger possibilities of avoiding the charges by changing route. To avoid rat-running in residential areas, the number of checkpoints had to be more than twice as many as in Stockholm. The result is that there are some unpopular barrier effects where the cordon cuts right through residential areas.

Another difference between the cities is that the model predicted effects on traffic volumes across the cordon and on bypasses less accurately than in Stockholm. The predicted effects were correct in terms of signs, both across the cordon and on circumferential roads, but not in terms of size. This is mainly due to a large number of relations where alternative routes to avoid the charges are available, and the fact that the model was not able to predict the route choice in these with high accuracy.

The public support is also lower in Gothenburg than in Stockholm. To understand why, we first note that a substantially larger share of the drivers in Gothenburg, compared to Stockholm, pay congestion charge regularly due to the lower public transport use. The lower congestion levels further imply that few drivers receive any substantial travel time benefits. Moreover, in Stockholm the congestion charges were marketed as a measure to improve the environment and to reduce congestion, and the use of the revenues was not at all in focus. In Gothenburg, however, it was more difficult to market the charges as an environmental measure. The real reason for introducing them, to collect tax revenue to finance an infrastructure package, could not be hidden altogether.

The differences in public opinion between Gothenburg and Stockholm indicate that to build public support for congestion charges, they must be effective in reducing travel time without making too many drivers substantially worse off. But they must also be marketed using positive moral or emotional values, such as improved environment, as suggested by Eliasson (2014).

A final key lesson drawn from Gothenburg is that the congestion charges were introduced only because the institutional setting at the time was shaped in a way that induced strong support from political parties. The public opinion, actual levels of congestion and benefits from congestion reduction were not critical factors. The Gothenburg case also demonstrates that introducing congestion charges as part of a bigger investment package deal, formed by a broad political consensus, is critical for support from many political parties and stakeholders. However, this increases the risk of large and inefficient investments that cannot be modified and improved, which in turn may reduce public support. 


\section{ACKNOWLEDGMENTS}

We are grateful to the City of Gothenburg and Västtrafik, the public transport company in Västra Götaland, for collecting and providing the data used in this study. We are particularly grateful to Karin Björklind and Per Bergström Jonsson, City of Gothenburg, to Ulla-Stina Ingemarsson and Åke Wessman, Swedish Transport Administration, and to Mats Tjernkvist, M4Traffic AB, for support, local knowledge and reflections. We are also grateful to VINNOVA, Sweden, who has funded this research.

\section{REFERENCES}

Björklind, K., Danielsson, J., Lindholm, P., Björk, H., Coulianos, M., Tjernkvist, M., 2014. Första året med Västsvenska paketet (The first year with the WestSwedish package) (No. 2014:3).

Börjesson, M., Eliasson, J., Beser-Hugosson, M., Brundell-Freij, K., 2012. The Stockholm congestion charges -5 years on. Effects, acceptability and lessons learnt. Transp. Policy 20, 1-12.

Börjesson, M., Eliasson, J., Brundell-Freij, K., 2014. Not Invented Here: Transferability of congestion charges effects. Transp. Policy Accepted to.

Carnovale, M., Gibson, M., 2013. The Effects of Driving Restrictions on Air Quality and Driver Behavior. eScholarship.

City of Gothenburg, 2013a. Restider i Göteborg - En jämförelse mellan 2012 och 2013 (Travel times in Gothenburg - A comparison between 2012 and 2013).

City of Gothenburg, 2013b. Förändrade resvanor: Trängselskattens effekter på resandet i Göteborg (Altered travel behaviour: The congestion charge and its effect on travel in Gothenburg).

Eliasson, J., 2014. The role of attitude structures, direct experience and reframing for the success of congestion pricing. Transp. Res. Part Policy Pract. 67, 81-95.

Eliasson, J., Börjesson, M., Brundell Freij, K., Engelson, L., Van Amelsfort, D., 2013. Accuracy of congestion pricing forecasts. Transp. Res. A 52, 34-46. doi:10.1016/j.tra.2013.04.004

Eliasson, J., Hultkrantz, L., Nerhagen, L., Rosqvist, L., 2009. The Stockholm congestion-charging trial 2006: Overview of effects. Transp. Res. Part A 43, 240-250.

Goodwin, P.B., 1989. The «rule of three»: a possible solution to the political problem of competing objectives for road pricing. Traffic Eng. Control 30, 495-497.

Ieromonachou, P., Potter, S., Warren, J.P., 2006. Norway's urban toll rings: Evolving towards congestion charging? Transp. Policy 13, 367-378. doi:10.1016/j.tranpol.2006.01.003

INRO Consultants Inc., 2010. EMME 3 User's Manual.

Jones, P., 1991. Gaining public support for road pricing through a package approach. Traffic Eng. Control 32, 194-196.

King, D., Manville, M., Shoup, D., 2007. The political calculus of congestion pricing. Transp. Policy 14, 111-123. doi:10.1016/j.tranpol.2006.11.002 
Kristoffersson, I., 2013. Impacts of time-varying cordon pricing: Validation and application of mesoscopic model for Stockholm. Transp. Policy Vol. 28, p. 51-60.

Larsen, O.I., Østmoe, K., 2001. The Experience of Urban Toll Cordons in Norway: Lessons for the Future. J. Transp. Econ. Policy 35, 457-471.

Manville, M., King, D., 2013. Credible commitment and congestion pricing. Transportation 40, 229-249. doi:10.1007/s11116-012-9430-9

Mellin, A., Nilsson, J., Pyddoke, R., 2011. Underlagsrapport till RiR 2011 : 28 : Medfinansiering av statlig infrastruktur.

Olszewski, P., Xie, L., 2005. Modelling the effects of road pricing on traffic in Singapore. Transp. Res. Part A 39, 755-772.

Phang, S.Y., Toh, R.S., 1997. From manual to electronic road congestion pricing: The Singapore experience and experiment. Transp. Res. Part E 33, 97106.

Riksrevisionen, 2012. Underlag och motiv för beslut i två stora infrastrukturobjekt - Västlänken och höghastighetsbanor - Bilaga 1.

Santos, G., 2005. Urban congestion charging: A comparison between London and Singapore. Transp. Rev. 25, 511-534.

Santos, G., Button, K., Noll, R.G., 2008. London Congestion Charging. Brook.Whart. Pap. Urban Aff. 177-234.

Santos, G., Shaffer, B., 2004. Preliminary results of the London congestion charging scheme. Public Works Manag. Policy 9, 164.

Saunders, J.P.F., 2005. The rise and fall of Edinburgh's congestion charging plans. Proc. ICE - Transp. 158, 193-201. doi:10.1680/tran.2005.158.4.193

Schaller, B., 2010. New York City's congestion pricing experience and implications for road pricing acceptance in the United States. Transp. Policy 17, 266-273.

SL, 2013. Fakta om SL och länet 2012 (Facts about SL and the county 2012) (No. SL 2013-6099).

Transportstyrelsen, 2014. Vad kostar det att ta ut trängselskatt/ infrastrukturavgift? (How much does it cost to collect congestion charges/infrastructure charges?) [WWW Document]. URL http://www.transportstyrelsen.se/Press/Kommentarer-ochfortydliganden/Vad-kostar-det-att-ta-uttrangselskattinfrastrukturavgift-/ (accessed 11.21.14). 